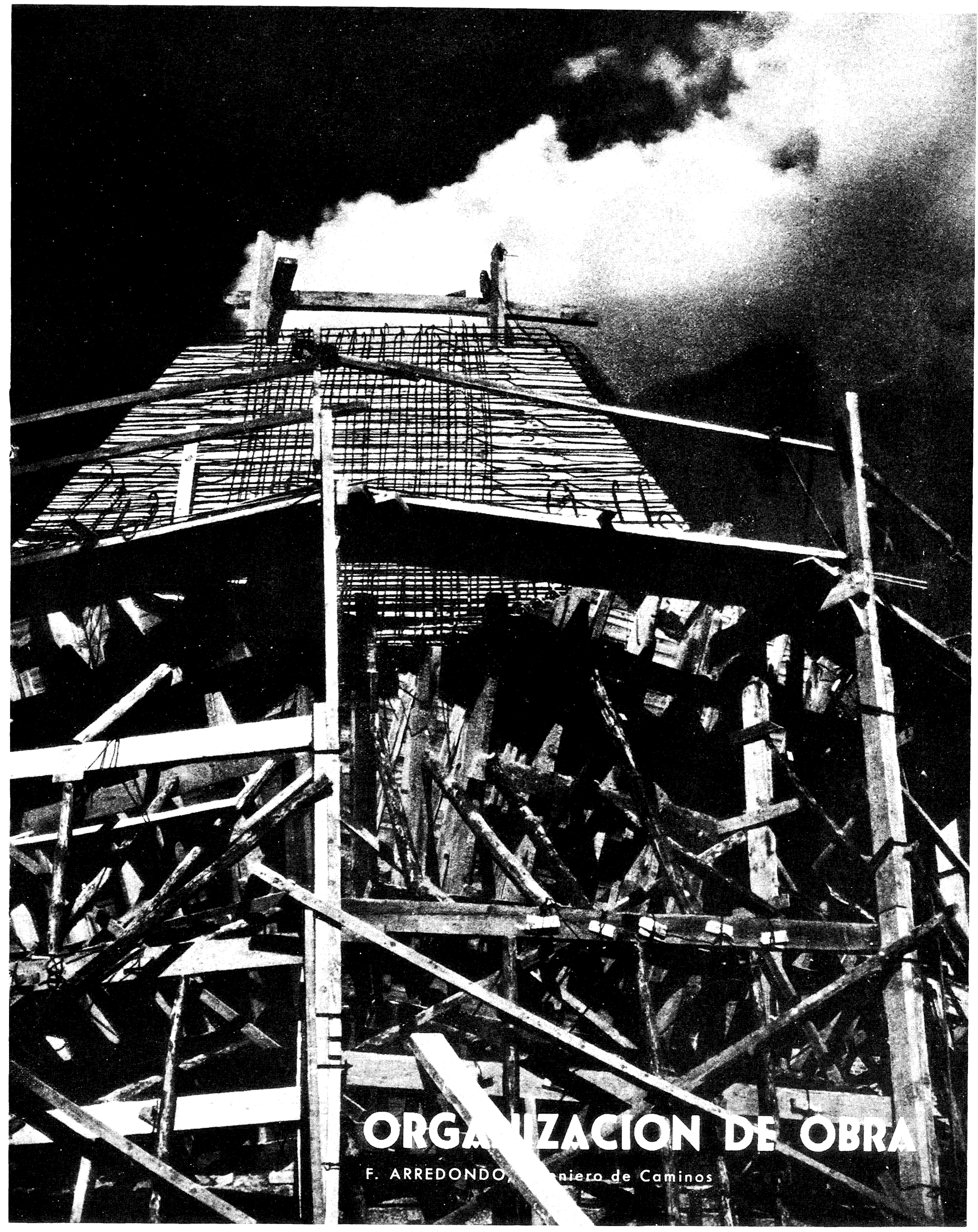




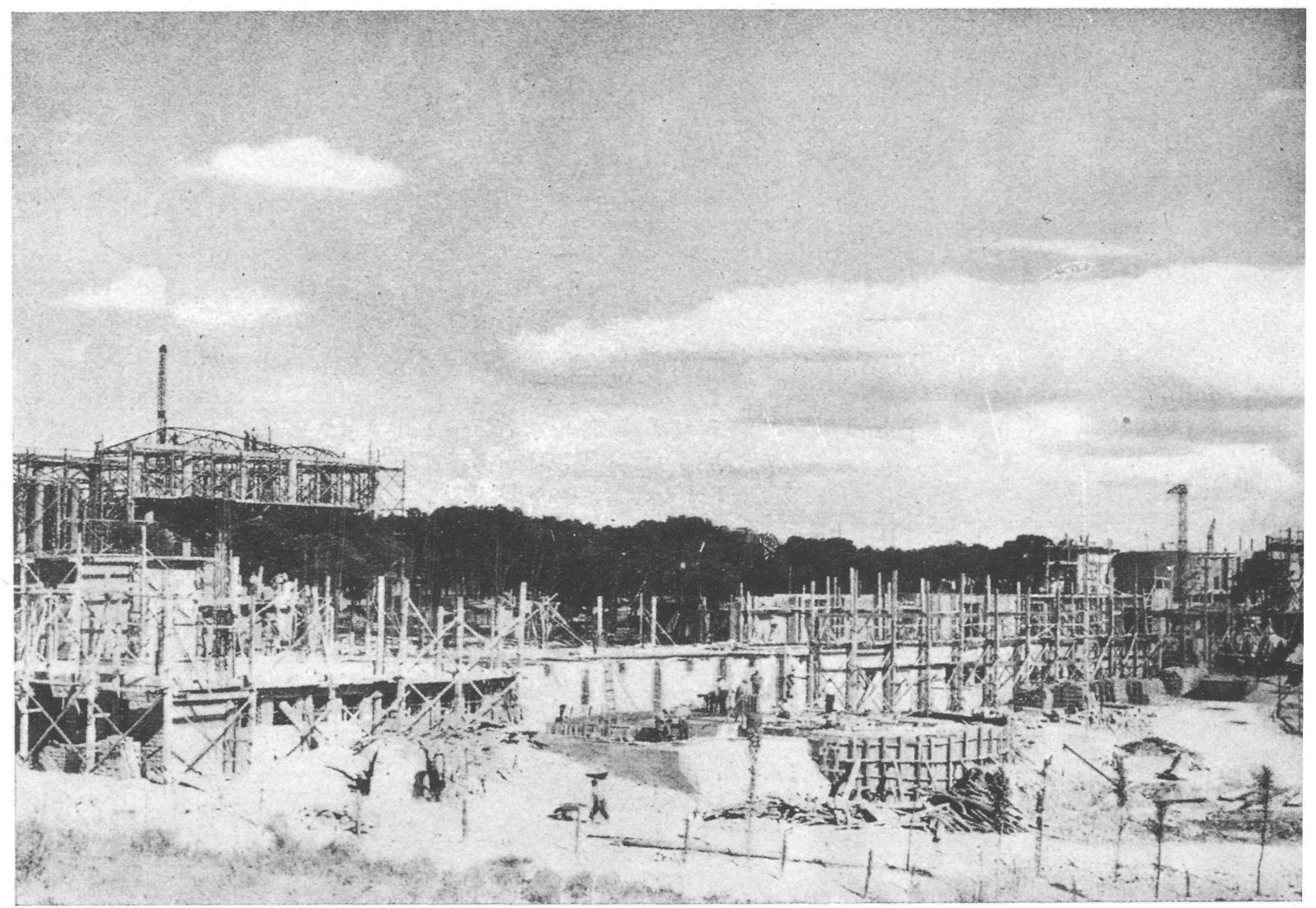

$730 \cdot 3$

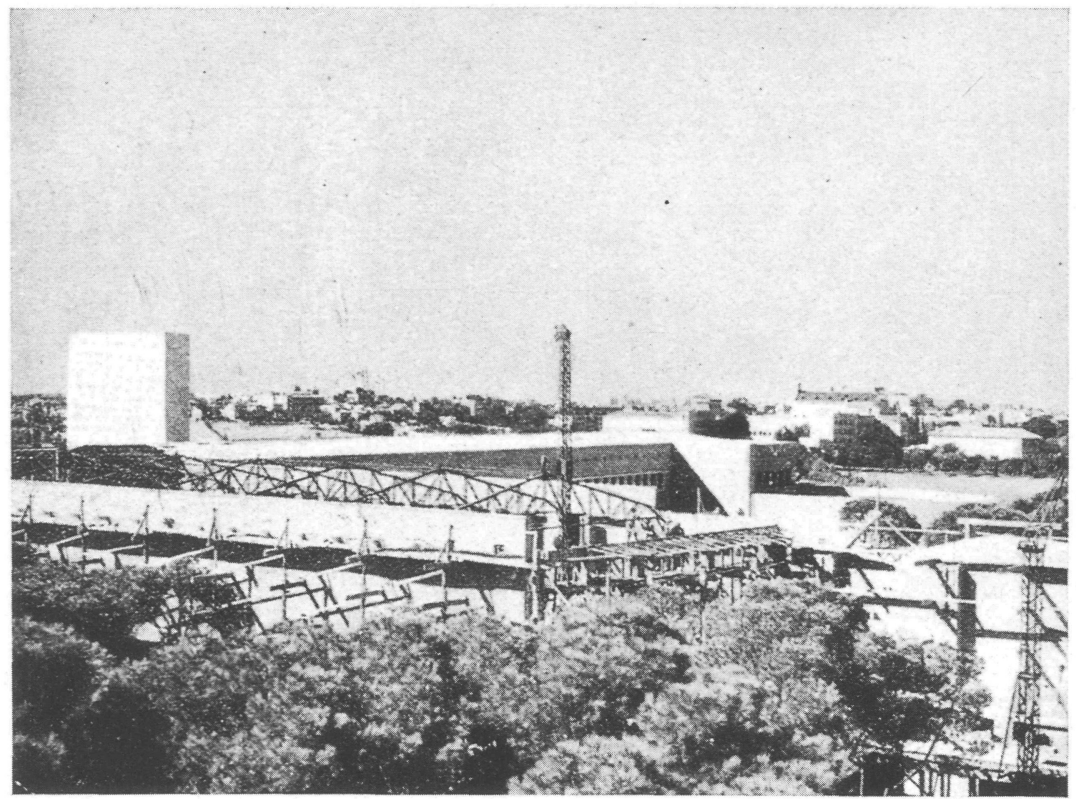

SINOPSIS

Se describe el sistema empleado para la construcción del nuevo edificio del Instituto, presentando gráficos de la marcha de la obra.

Se incluye relación de suministradores, asi como los principales materiales empleados.
Siguiendo órdenes de la Superioridad, y como quiera que los trabajos hahían de llevarse al ritmo más acelerado posible-por razones funcionales, técnicas y económicas en las que no es preciso insistir-inmediatamente de adquirir los terrenos y proceder al cerramiento de la parcela se dió comienzo a las obras, y a los 34 meses de clavada la primera estaca para el replanteo, está no solamente terminada sino en uso desde hace seis meses.

En una obra de este tipo, este reducido tiempo constituye un verdadero récord, ya que se trata de una obra con un volumen de $62.800 \mathrm{~m} .^{3}$ y este récord es mucho más ostensible si se tiene en cuenta que se han empleado materiales nuevos y sistemas constructivos que, según creemos, no han sido empleados hasta ahora, y que son fruto, en una gran parte de las investigaciones de las diversas secciones de estudio, 


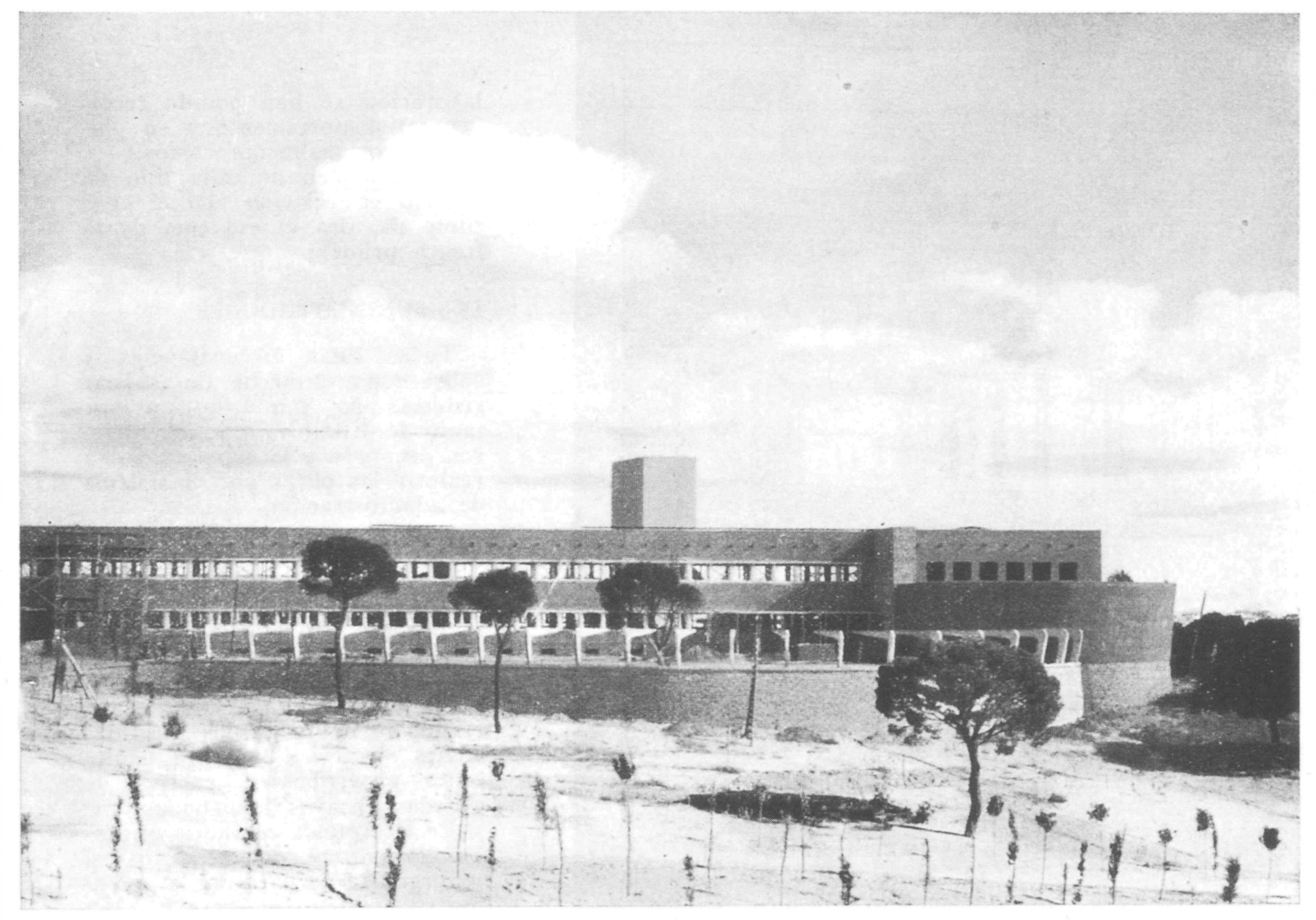

con lo cual nuestro nuevo edificio ha sido un dilatado campo de experimentación para nuestros especialistas que han tenido ocasión de ver comprobadas en la realidad las ventajas previstas en las investigaciones teóricas y los inconvenientes que no se habían previsto.

Además, dadas las características del proyecto y por no ajustarse la obra a los sistemas constructivos clásicos ha resultado, en determinados casos, difícil establecer la técnica más conveniente para su ejecución y los medios auxiliares más adecuados, lo que ha dado origen a tanteos y ensayos de soluciones posibles, pero una vez conseguida la solución óptima se ha llevado a cabo la obra siguiendo sistemas racionalizados, basados en la industrialización de la mayoría de sus elementos y ha constituído, como se proponía, una enseñanza muy interesante y una pauta a seguir en obras similares.

Por otra parte, la obra presentaba una gran complejidad por los diversos elementos que la constituiat y la simultaneidad de los trabajos de los instaladores ha creado algu. nas veces problemas tales que solo merced a un elevado espíritu de co-

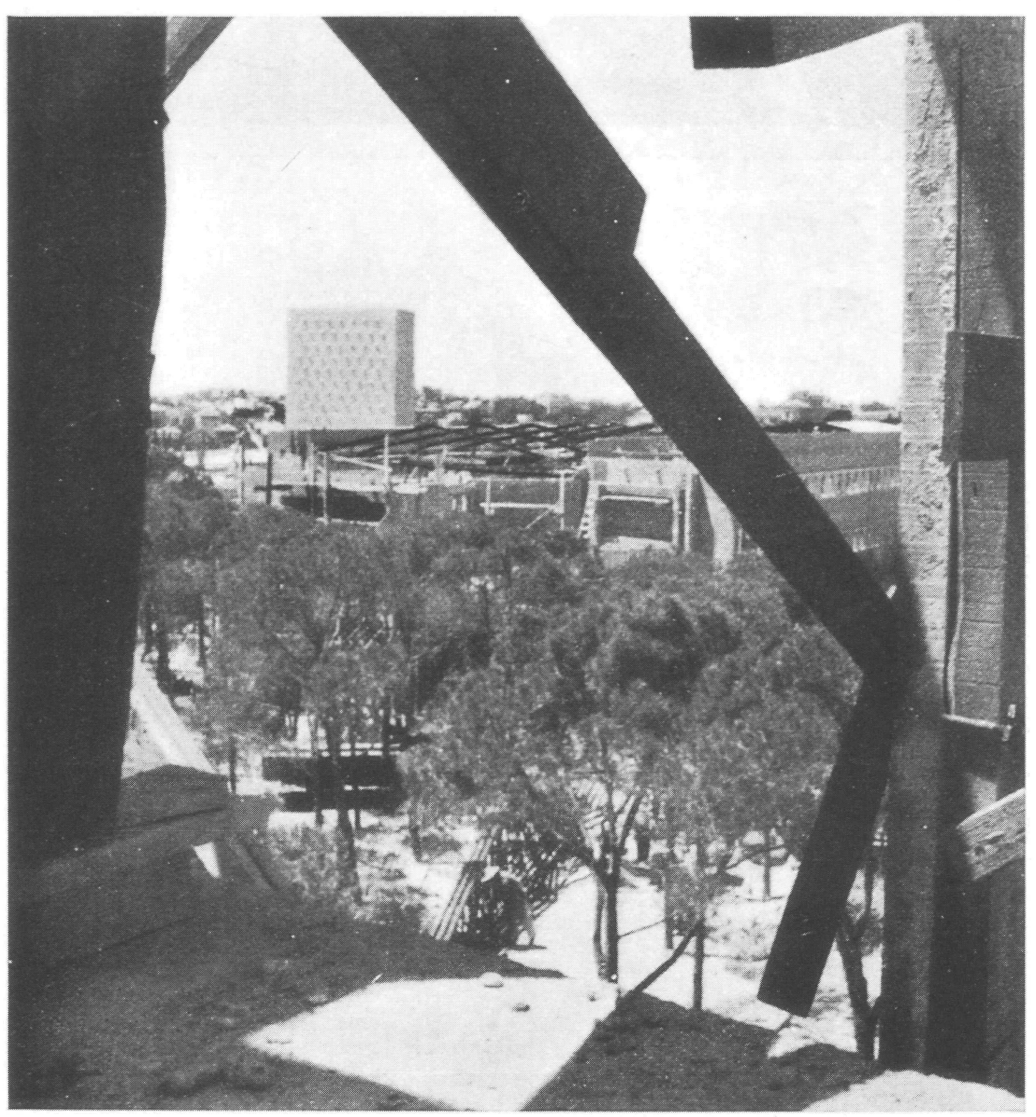




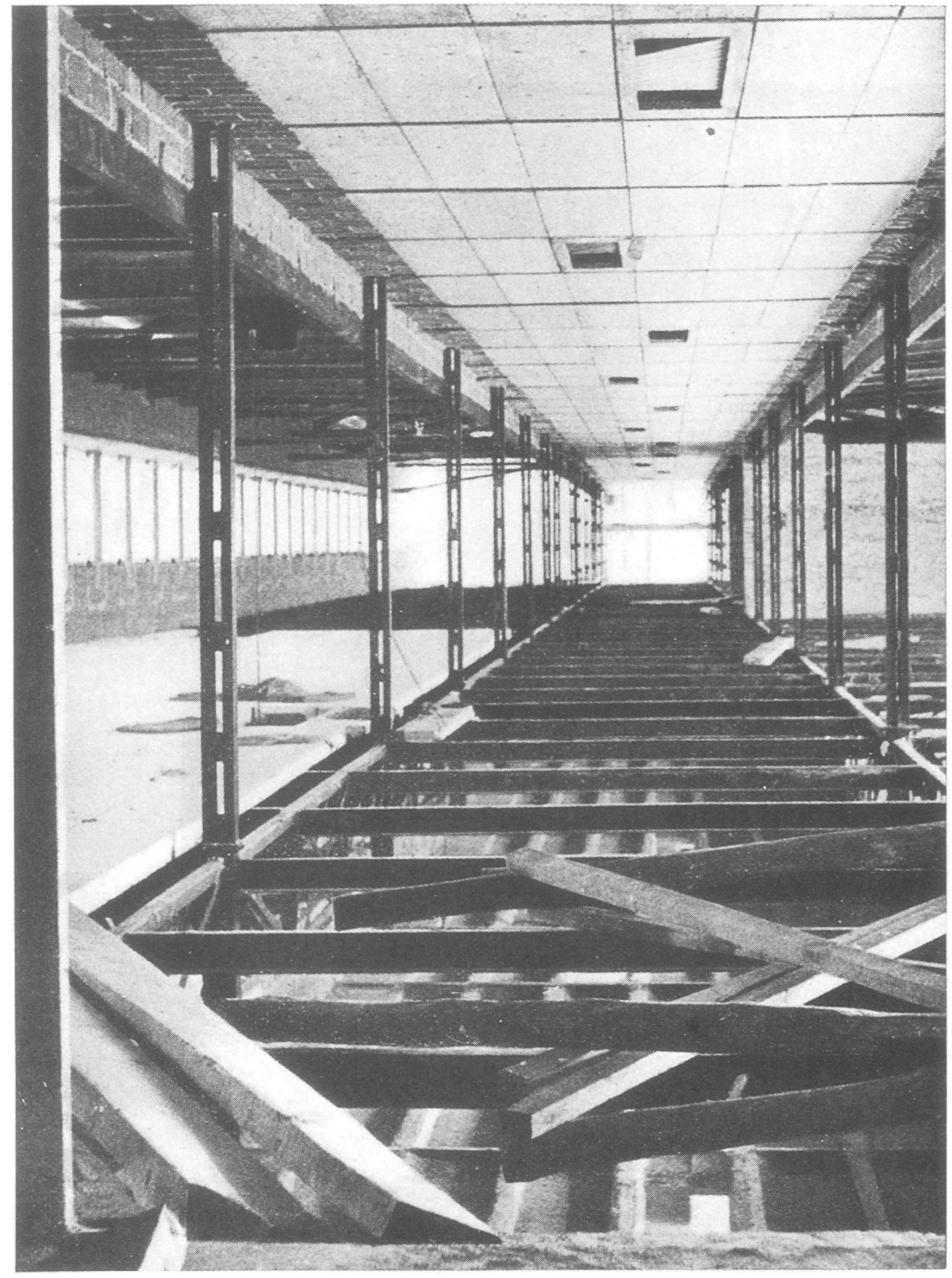

laboración se han podido resolver satisfactoriamente y en plazos excepcionalmente cortos.

Del volumen de cada tipo de trabajo en relación con el conjunto da idea el esquema de la figura primera.

\section{LOS SUMINISTRADORES}

Todas estas circunstancias y sobre todo el hecho de utilizar sistemas no empleados, y por tanto de difícil valoración, hicieron decidirse a la superioridad a realizar las obras por el sistema de administración.

Pero lo mismo desde el punto de vista técnico que desde el administrativo pueden diferenciarse dos épocas en la construcción la primera, de unos ocho meses de duración, de organización general, dedicada especialmente a obras auxiliares tales como el cerramiento de la parcela, instala. ciones eléctricas de obra, almacenes provisionales, casetas de guardas, ensayos de sistemas, etc.

En la segunda comienza el desarrollo normal de los trabajos, ya organizados para dar el máximo rendimiento y llevar la obra a la velocidad prevista.

En la primera etapa fué necesario apoyarse materialmente en la organización de Agromán Empresa Constructora, ' S. A., quien nos ha suministrado personal y material con la mayor diligencia y espíritu de colaboración, y en ella nos fué posible fijar ya un avance de los rendimientos futuros, de las instalaciones auxiliares y de los planes de trabajo que se habían de seguir más tarde.

En la segurida etapa la obra presentó menos incógnitas y se pudo llevar a cabo por los sistemas de administración, recabando de la citada empresa constructora la mano de obra, y la cooperación de sus servicios y maquinaria auxiliar, pero las adquisicicnes de materiales se gestionaron directamente por la oficina montada a tal efecto en el Instituto.

En esta segunda época ya había en la obra tajos abiertos que pudieron llevarse a cabo por los sistemas tradicionales, tales como ciertas unidades de fábricas de ladrillo, movimientos de tierras, hormigonados, determinada parte de las estructuras metálicas, instalaciones eléctricas, sanitarias de todo orden en las que, según conveniencias propias de la obra, se pudo seguir el prccedimiento de adjudicarlas en destajos parciales a industriales solventes mediante los concursillos restringidos preceptivos. 


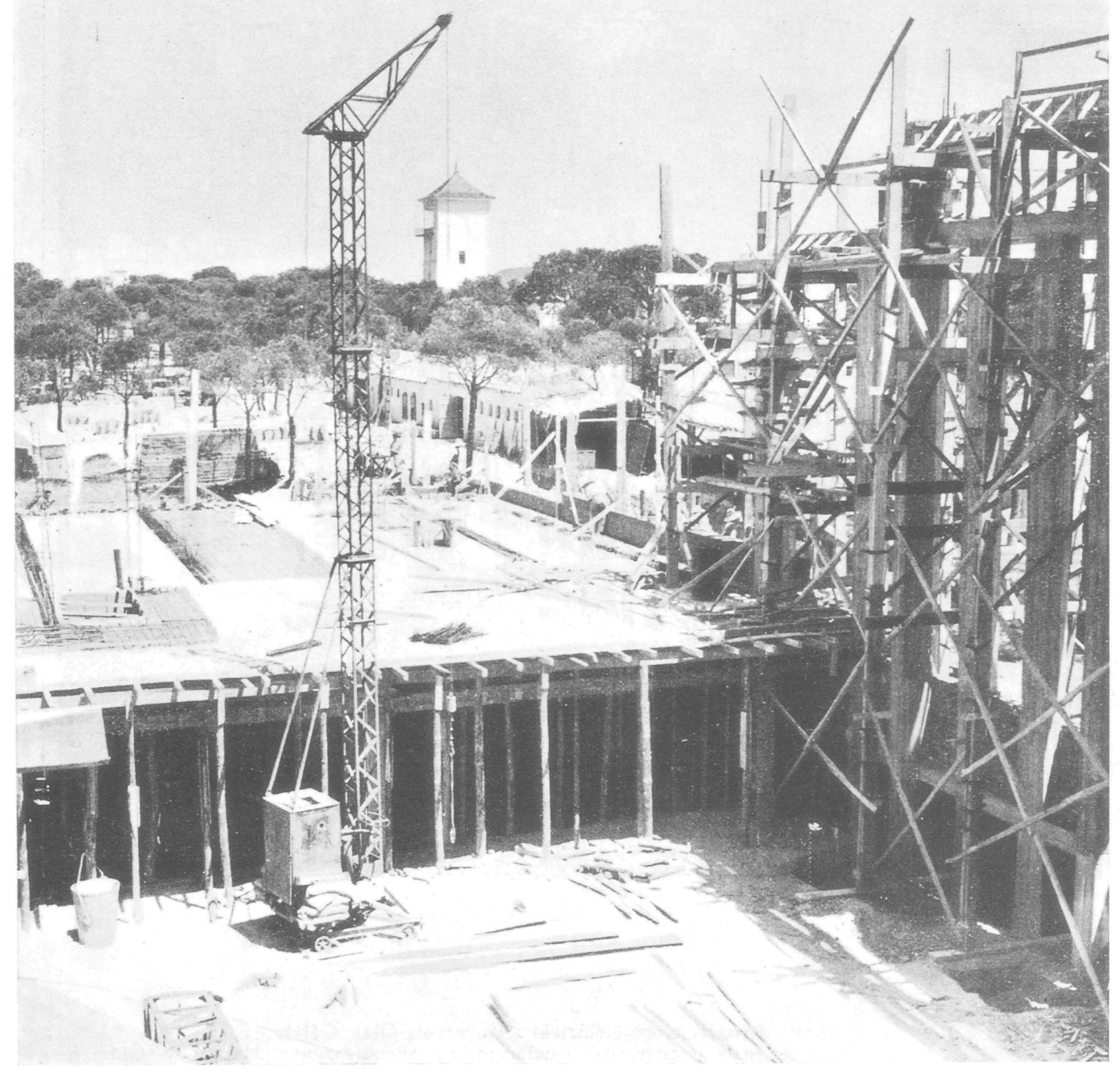

La labor y prestación de Agromán E. C., S. A., son dignos de todo elogio, pues no se redujeron al magnífico apoyo inicial de poner a nuestra disposición obreros, técnicos, maquinaria y todos los elementos necesarios, sino que con su organización y entusiasmo ha allanado de manera ejemplar las dificultades de suministros de materiales y maquinaria auxiliar y ha prestado su colaboración eficaz a toda iniciativa o modificación.

En especial hemos de significar nuestro agradecimiento al Ingeniero de Caminos, don José Gascón, encargado de la obra por parte de dicha empresa, quien con su reconocida experiencia ha secundado en todo momento los planes e iniciativas de la dirección de obra con tan gran entusiasmo y eficacia que ha demostrado una vez más su vasta capacitación, depurada técnica y sincera cordialidad.

Aparte de esta empresa constructora, han realizado instalaciones, ejecutado trabajos o suministrado materiales las siguientes firmas :

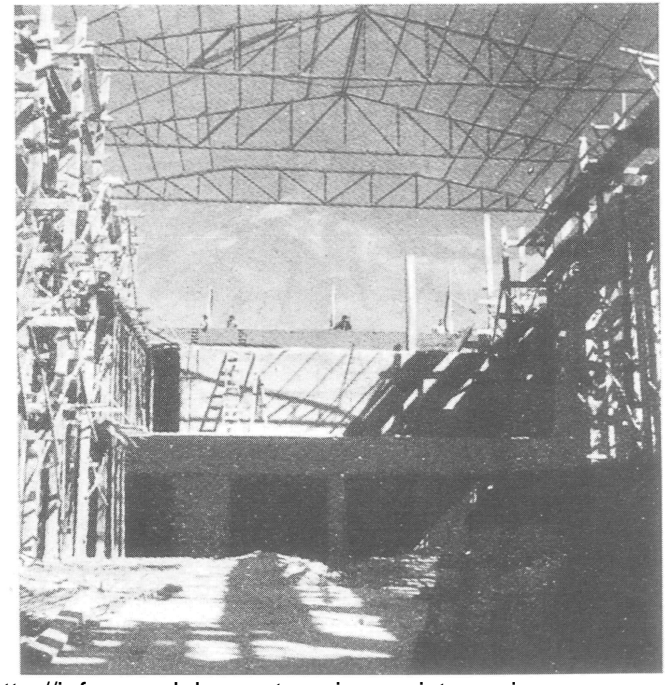

http://informesdelaconstruccion.revistas.csic.es 

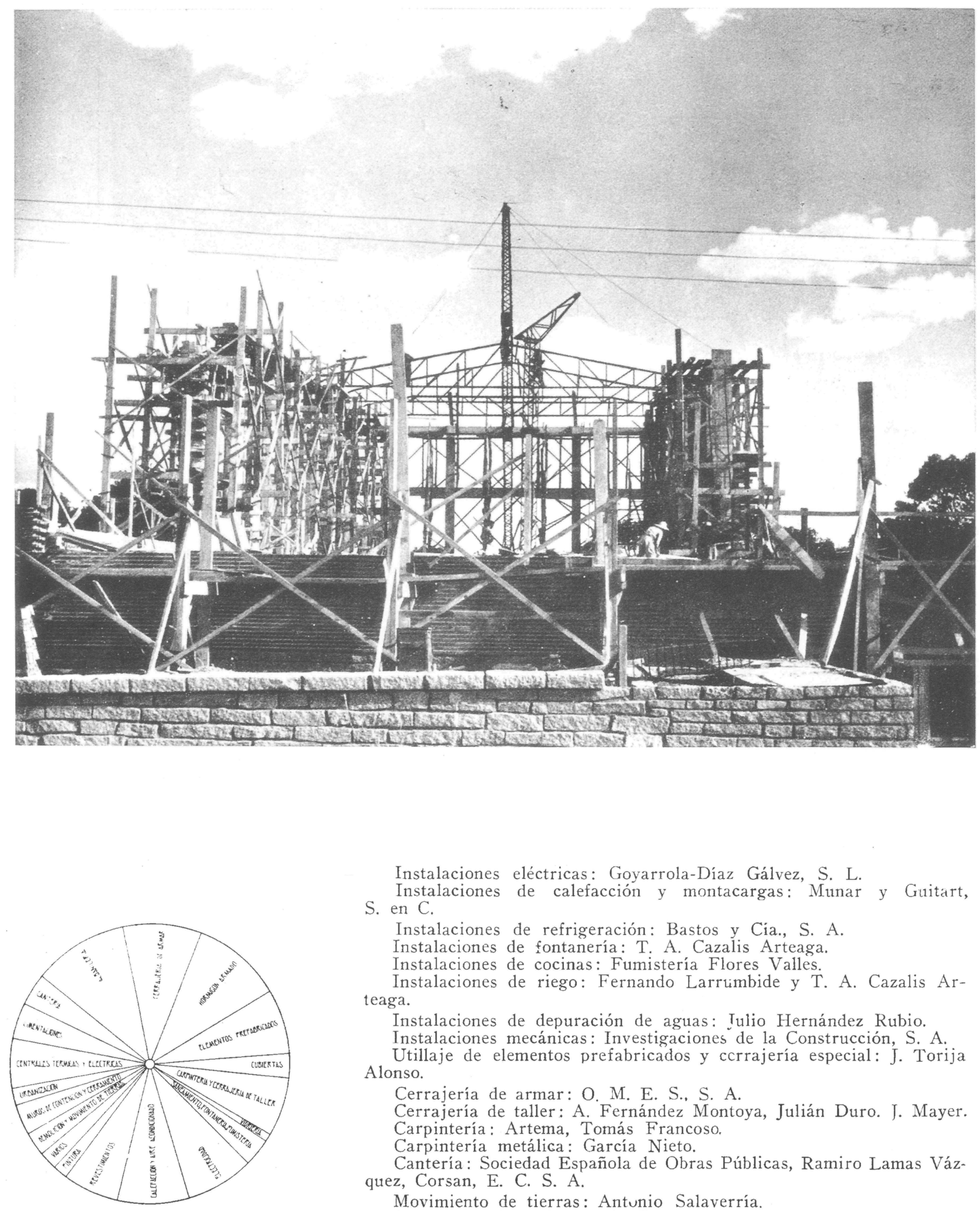

Instalaciones eléctricas: Goyarrola-Díaz Gálvez, S. L.

Instalaciones de calefacción y montacargas: Munar y Guitart, S. en C.

Instalaciones de refrigeración: Bastos y Cía., S. A.

Instalaciones de fontanería: T. A. Cazalis Arteaga.

Instalaciones de cocinas: Fumistería Flores Valles.

Instalaciones de riego: Fernando Larrimbide y $\mathrm{T}$. A. Cazalis Arteaga.

Instalaciones de depuración de aguas: Iulio Hernández Rubio.

Instalaciones mecánicas: Investigaciones de la Construcción, S. A.

Utillaje de elementos prefabricados y ccrrajería especial: J. Torija Alonso.

Cerrajería de armar: O M. E S. S A

Cerrajería de taller: A. Fernández Montoya, Julián Duro. J. Mayer. Carpintería: Artema, Tomás Francoso.

Carpintería metálica: García Nieto.

Cantería: Sociedad Española de Obras Públicas, Ramiro Lamas Vázquez, Corsan, E. C. S. A.

Movimiento de tierras: Antunio Salaverría.

Solados y alicatados: Luis Guadaño Peñalver.

Pintura: Pardo y Pascual. 

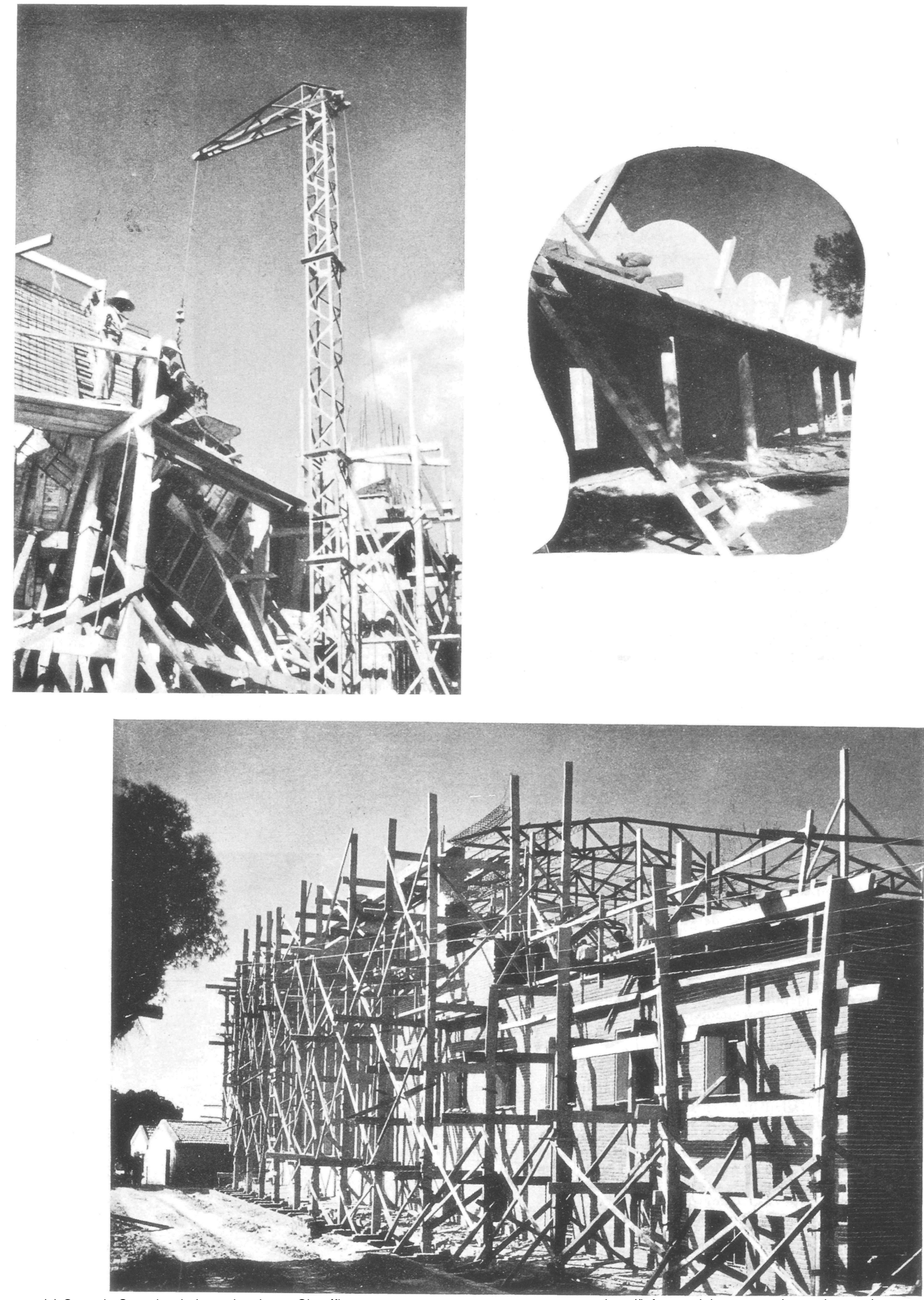


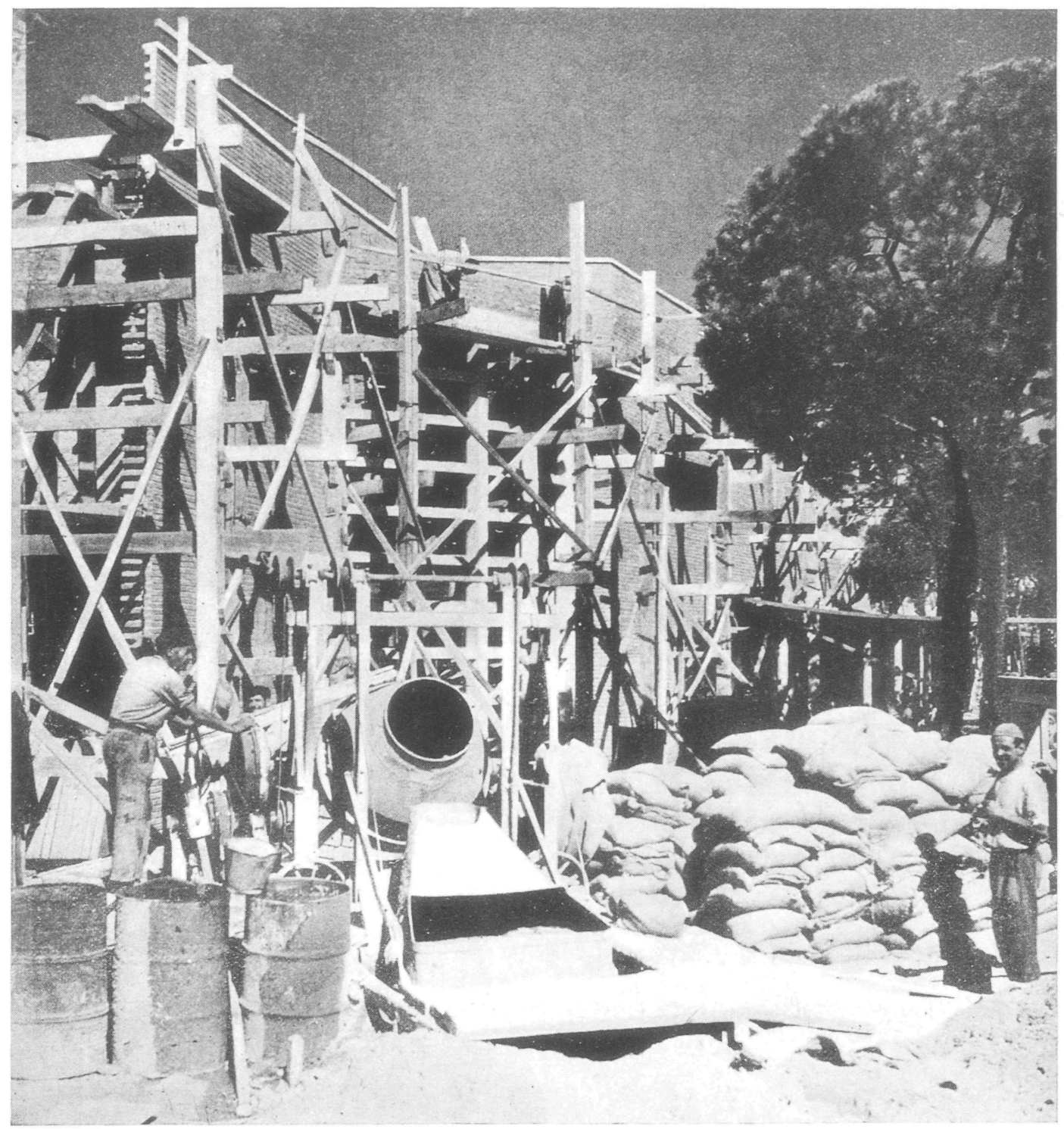

Aislamientos térmicos: Enrique Miret Espoy, Explotación de Industrias, Comercio y Patentes, S. A.

Vidriería: Sucesor de G. Pereantón, S. A.

Paviméntos de terrazo: Tecnicrom, S. A.

Pavimentos asfálticos: Peninsular de Asfaltos y Construcciones, S. A.

Cubiertas: Uralita, S. A

Cercas metálicas: El Progreso Industrial, A. Leoz.

Toldos: La Reposición.

Jardinería: R. Ortiz Ferré

Recubrimientos de aluminio: Jesús Miralles.

Ebanistería: Artema, José López Gómez, Talleres Serrano, Tomás Francoso.

Ladrillos: Cerámica Puig, F. de Ladrillos de Valderrivas, S A.,

Cerámica Madrileña, Cerámica Estela.

Ladrillos refractarios y gres: Cerámica Industrial Castellana. Grasas, aceites, accesorios: Auto-Suministros.

Tuberías de cemento: Metalización y Construcciones, S. A.. Sociedad de Tubos Aglomerados y Centrifugados, S. A.

Botas, mangueras, correas, etc.: Francisco Castellote.

Fosas sépticas: Cimarmé.

Material eléctrico para obra: Electrofil Madrid, S. A., Jubindo, S. L.

Apliques de luz; Fluma, S. A., Terán y Aguilar, S. A.

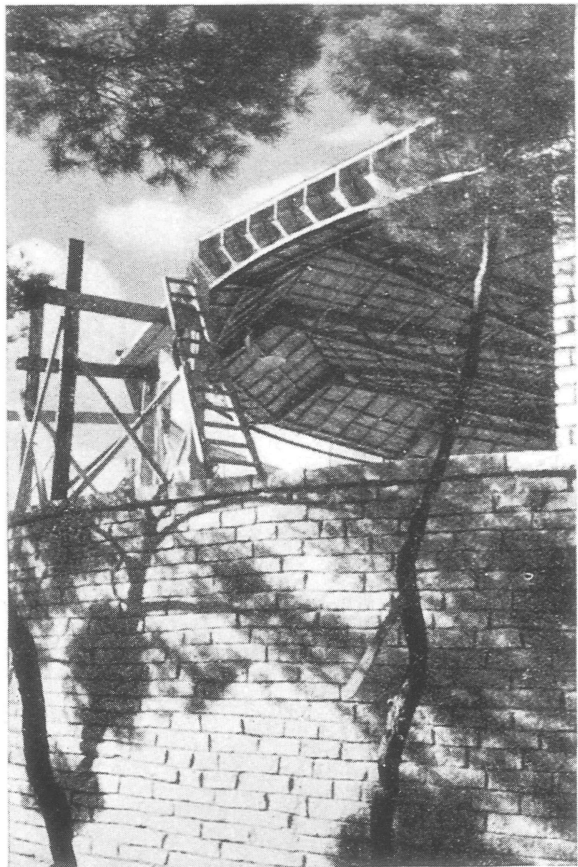




\section{de obra}

Equipos fluorescentes: Fluorescencia y Televisión Ibérica, S. A.

Esterilizadores de agua: Foncal.

Caja de Caudales: Fortis, S.A.

Cal: Lasical, S. A.

Tuberías metálicas: Hierros y Metales Sur, S. L., Tubos y Hierros Industriales, S. A.

Lías y tiros de esparto, espuertas, etc: Hijos de Modesto Dafouz.

Corcho: Hispano Corchera, S. A., I. C. A.

Ferretería Igartúa, S. A., F. del Pozo, Vda, de Félix Román, Ferretería Hernández.

Cámaras de descarga automática: Maquinista y Fundiciones del Ebro, S. A.

Bidones: Jaime Martínez.

L on as, cuerdas, etc: Francisco Mora-Rey.

Aridos: Eduardo Palomo. Productos químicos y de limpieza: Manuel Riesgo.

Impermeabilizantes, despegadores de encofrados, etc.: Antares, S. A.

Forjados cerámicos: Río Cerámica de Alcalá, S. A.

Madera: Uranga, Unión

Maderera Española, S. A. Yeso: Yesos Marín.

A $r \mathrm{~m}$ arios frigoríficos:

Auto Electricidad, S. A.

Indicadores de temperaturas: Thermo Electro, Sociedad Anónima.

\section{MARCHA DE LA OBRA}

En el gráfico que se acompaña puede verse el desarrollo de los trabajos y la duración de los mismos en las diferentes zonas del edificio. Las interrupciones de algunos de los tajos corresponden a la necesidad y urgencia de terminación de otros con objeto de hacer utilizables las naves correspondientes, pues es sabido que a los 28 meses de iniciado el replanteo todos los servicios del Instituto estaban funcionando en sus nuevos locales.

En otro gráfico se presenta la evolución de la mano de obra a ló largo de todo el proceso constructivo, clasificada en los diversos oficios. Este gráfico se refiere exclusivamente a la obra de fábrica y no a las instalaciones, pintura, carpintería, etc.

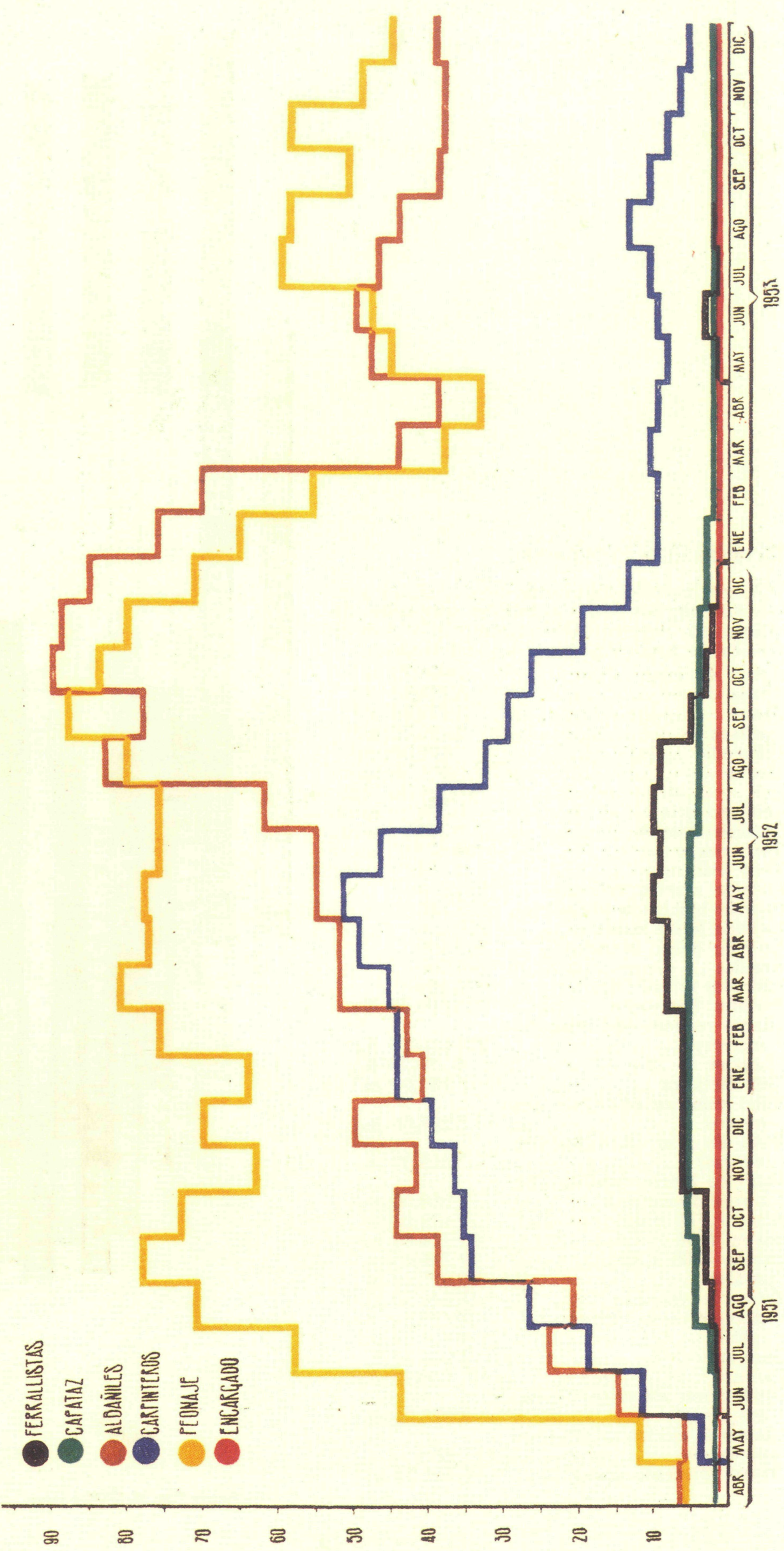




\section{MATETERIALES EMPLEADOS}

A continuación reseñamos las cantidades gastadas de algunos de los materiales empleados. Se refiere esta relación exclusivamente a la obra de fábrica, es decir, sin contar las instalaciones.

Arena de miga $\ldots \ldots \ldots \ldots$

Arena de río $\ldots \ldots \ldots \ldots$

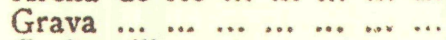

Garbancillo

Piñoncillo

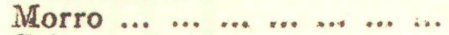

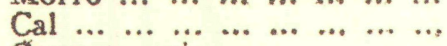

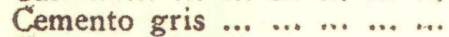

Cemento blanco $\ldots . . . . \quad \ldots \ldots$

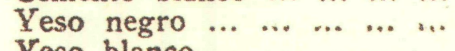

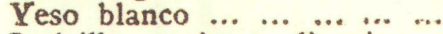

Ladrillo macizo ordinario ...

Ladrillo macizo de paramento.

Ladrillo hueco doble

Ladrillo hueco sencillo .......

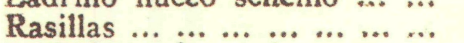

Ladrillos refractarios ... .......

Perfiles laminados .......

Hierro redondo (distintos diá-

Alambre de atar ... ... ... ...

Tela metálica ...............

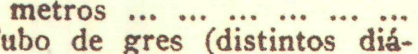

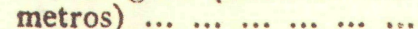

Tubo de hierro fundido (distintos diámetros) ... ......

Riostra $(75 \times 52) \ldots \ldots$

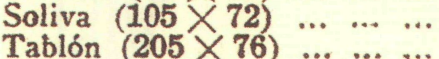

Tablón $(205 \times 76) \ldots \ldots$

Puntales $\ldots \ldots \ldots \ldots \ldots \ldots$

Puntas (diversos tamaños) ....

Vitrofib $\ldots \ldots \ldots \ldots \ldots$

$\begin{array}{llllllll}\text { Gasolina } & . . & \ldots & \ldots & \ldots & \ldots & \ldots & \ldots\end{array}$

Carburo ... $\ldots$... $\ldots \ldots$. $\ldots \ldots$

sos tipos) $\ldots \ldots \ldots \ldots$
Lamparas eléctricas potencias) ...............

Cristal (diversos tipos) .......
$994,75 \mathrm{~m}^{3}$

$5.674,40 \mathrm{~m}^{3}$

$5.277,50 \mathrm{~m} .3$

$2.295,25 \mathrm{~m}^{3}$

$500,50 \mathrm{~m}^{3}$

$307,75 \mathrm{~m}^{3}$

$23.710,00 \mathrm{Kg}$.

69.823 sacos

2.216 sacas

19.829 sacos

1268 sacos

971.900

538.850

259.230

300.100

203.700

19.150

$213.000,00 \mathrm{Kg}$.

$270.630,79 \mathrm{Kg}$.

$6.110,20 \mathrm{Kg}$.

$950,00 \mathrm{~m}^{2}$

$2.207,00 \mathrm{~m}$.

$510,80 \mathrm{~m}$.

$1.058,00 \mathrm{~m}$.

$17.438,30 \mathrm{~m}$

$11.734,80 \mathrm{~m}$.

$17.719,65 \mathrm{~m}$.

$9.923,20 \mathrm{~m}$.

$15.344,94 \mathrm{m.}^{2}$.

$10.004,40 \mathrm{Kg}$.

$4.590,00 \mathrm{~m}^{2}$

$1.900,00$ L

$206,15 \mathrm{Kg}$.

$4.930,00 \mathrm{~m}$.

564

$1.701,74 \mathrm{~m}^{2}$

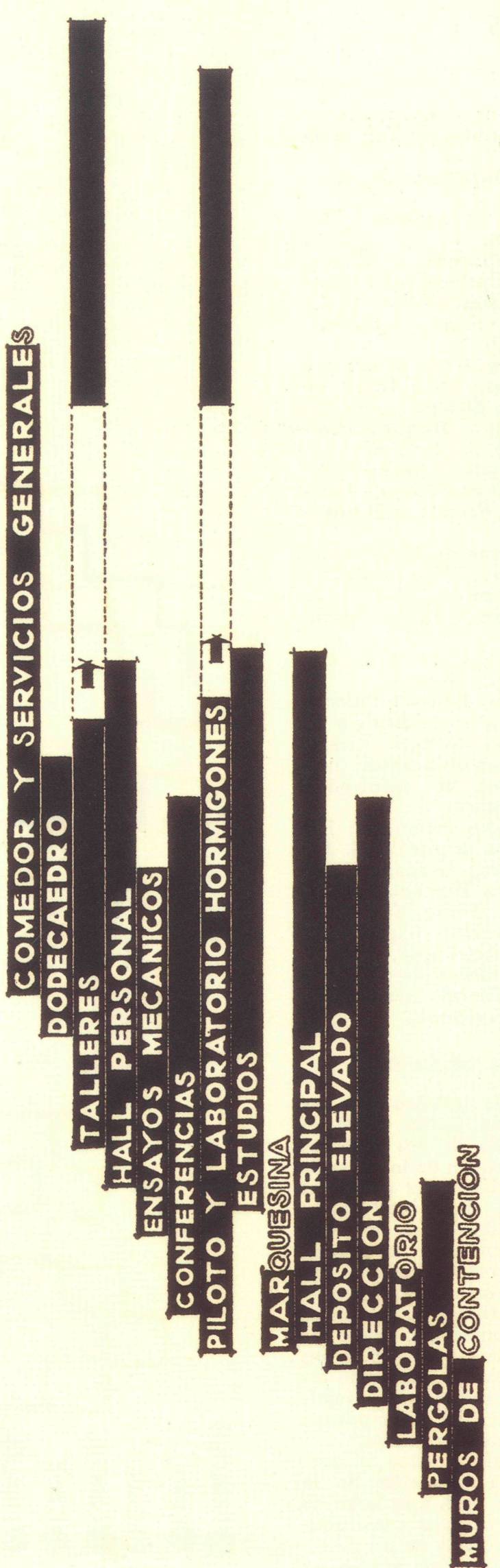

通 